https://helda.helsinki.fi

\title{
Praxis, politics and the future : a dialectical critical realist account of world-historical causation
}

\section{Patomäki, Heikki Olavi}

2017

Patomäki , H O 2017 , ' Praxis, politics and the future : a dialectical critical realist account of world-historical causation ', Journal of International Relations and Development, vol. 20 , no. 4 , 2016.17 , pp. 805-825 . https://doi.org/10.1057/jird.2016.17

http://hdl.handle.net/10138/297754

https://doi.org/10.1057/jird.2016.17

acceptedVersion

Downloaded from Helda, University of Helsinki institutional repository.

This is an electronic reprint of the original article.

This reprint may differ from the original in pagination and typographic detail.

Please cite the original version. 
This is a post-peer-review, pre-copyedit version of an article published in Journal of International Relations and Development, vol. 20, issue 4. The final authenticated version is available online at: https://doi.org/10.1057/jird.2016.17.

Praxis, politics and the future: a dialectical critical realist account of world-historical causation Heikki Patomäki

Department of Political and Economic Studies, P.O. Box 54, 00014 University of Helsinki, Finland E-mail: heikki.patomaki@helsinki.fi

\section{Abstract}

Both positivists and post-positivists have misunderstood causation. By explaining why there are no stable and uncontested empirical invariances in IR, critical realism has pushed theoreticians and practitioners to reflect critically upon the conception of causation they have so far taken for granted. However, the original CR claim about radical asymmetry between explanation and prediction has turned out to be misleading. Not everything is irregular. Policy and action are future-oriented and require at least some predictive capacities. In this paper, I explore ways in which practically adequate knowledge can draw on historical analogies, social organisation of time and space, contrastive demiregularities and explanatory theories and models. Anticipations of future possibilities - that may concern even the global system as a whole - must be made systematically revisable and be reflexively aware of their own involvement in shaping the course of history. The concept of probability, too, can and must be rethought from this perspective. Finally, I argue that the notion of reflexive selfregulation of social systems has interesting parallels in the theory of history, ethics and politics of dialectical CR, understood as a theory of freedom.

Keywords: Explanation, historical analogy, normative discourse, open system, prediction, probability, reflexivity, scenario 


\section{Introduction}

By the 2010s, it is agreed at least in some corners of IR that critical realism (CR) has made an important contribution to the study of causation. For example, Patrick Thaddeus Jackson (2010) in his widely acclaimed book depicts $\mathrm{CR}$ as one of the four main meta-theoretical positions in IR. CR emerged as a philosophy of science and social sciences in the 1970s and 1980s. It was introduced into IR in the late 1980s and early 1990s (Wendt 1987; Patomäki 1991; 1992). Subsequent contributions (Wight 1996; 2006; Patomäki and Wight 2000; Patomäki 1996; 2002; Joseph 2002; 2012; Kurki 2008) have fleshed out further critical realist possibilities for IR research.

Although it was grounded in realist developments in the philosophy of science in the 1960s and early 1970s (Bunge 1959; 1963; Harré 1970; Harré and Madden 1975; Hesse 1966), CR has most often been associated with the works of Roy Bhaskar (especially 1975/1997; 1979; 1986; 1989). The term critical realism was coined in the late 1980s. The basic CR claims have been reiterated time and again in various disciplinary contexts. The first claim is that ontology must come first, since it is the nature of objects that determines their cognitive possibilities. The search for invariant regularities is futile. The world must be differentiated, layered, structured, causally efficacious and open-systemic for our scientific knowledge about it to be possible. The real world is characterised by multiple, overand plural determination and thus causation is complex. The world is not only complex but also changing.

In IR in the late 1980s and early 1990s, many, especially young scholars felt that the discipline was in crisis. No cumulative learning seemed to have taken place (this was the topic of Lapid's (1989) famous 'third IR debate' article). ${ }^{1}$ Despite decades of systematic efforts at identifying regular connections between variables related to war and peace, and conflict and cooperation, there appeared to be only one genuine candidate left for an empirical invariance, the democratic peace hypothesis and even that was contested (for current assessments of the problems of the democratic peace hypothesis, and for criticism of its misuse in political practice, see Ish-Shalom 2013; Barkawi 2015). Various post-positivist alternatives have been proposed, but they struggle with their own 
contradictions and dead-ends (Lapid 1989; Patomäki and Wight 2000) and have tended to develop into isolated fragments that do not truly communicate with the wider field (Ferguson and Mansbach 2014).

Before CR entered the field of IR, hardly anyone questioned empirical invariances as necessary for causality (Suganami 1996 being a near-simultaneous exception). It can be easily shown that the idea that causality involves empirical invariances presupposes closed systems. Constant conjunctions of events obtain only in the absence of outside intervention and qualitative variation (see Bhaskar 1979: 160). Where a genuine, non-changing causal mechanism has been isolated, we can say that 'every time $\{\mathrm{A}, \mathrm{B}, \mathrm{C} \ldots\}$ occurs, $\mathrm{X}$ follows'. But entities do change and systems are more or less open except when carefully set up experimental conditions obtain.

In fact, 'if we retain a Humean definition of causation as regular succession, we will discover no causal laws outside astronomy, where the incapacity of other mechanisms to deflect heavenly bodies from their courses approximates to a natural closure' (Collier 1994: 34). Causal agents, mechanisms and complexes produce effects in open systems. Therefore it is wrong to assume that causality can be analysed in terms of simply necessary or sufficient conditions; yet, this is presupposed if one talks about empirical invariances. Empirical outcomes are the contingent results of a complex interplay of manifold agents, forces, mechanisms and processes.

While the CR conception of causation in open systems explains why there are no uncontested empirical invariances in social sciences, it also seems to imply that there is a radical asymmetry between explanation and prediction. This means that we can explain the past and the present, but not predict the future. At first, the CR insight may appear so important - it rescues causal analysis from empiricism that has failed to result in cumulative learning in IR - that its downside may seem irrelevant. But, as pragmatists ${ }^{2}$ have insisted, is it not that adequate social science consists in our ability to act in, and shape, the world (Jackson 2016)? The problem is that all social action occurs in time and is orientated towards the future. What matters for practical action is the future. 
What is to be done now? To answer this question - acutely urgent to all political actors - we need to know at least something about the ongoing processes and their probable effects and about the possible and likely consequences of our own actions and policies, both necessarily lying in the future (e.g. Chernoff 2005: 136). The key question is thus: if causation is complex and open-systemic, and if there is an asymmetry between explanation and prediction, does this really mean that there is little, if anything, that social sciences can say about the future? One consequence of the alleged asymmetry between explanation and prediction is that history, while of course recognised as important and in many ways also political, is unable to give significant guidance to policy, or to political praxis more generally. ${ }^{3}$

In this article, I argue for the possibility of rational anticipations of the future while accepting (for the most part) the CR framework. I start by outlining the CR conception of causation and showing its pragmatic underpinnings. The Greek word pragmatikos means, amongst other things, 'fit for action', and action is always future-oriented. Second, I discuss in some detail, and through various stages, how critical realists have come to acknowledge that not everything is irregular either, and that action and policy require at least some predictive capacities (see also Patomäki 2010b, for a friendly critique of $\mathrm{CR}$ as a philosophical system and practice). Action is coordinated and society organised in a manner that makes many things predictable. Some social mechanisms exhibit relatively regular empirical connections, often tending to reproduce the existing social structures, while some feedback loops are reflexive and possibly change-oriented. There are negative and positive feedback loops; some processes are self-reinforcing. Various effects can be anticipated.

Arguably, the very existence of society is dependent on future-oriented human concepts and activities. This complicates the picture. Hence further steps need to be taken. Even when our anticipations of future possibilities concern the global system as a whole, they must be reflexively aware of their own involvement. This makes it all the more important that anticipations are understood as methodically revisable. The notion of probability, too, should be rethought from this perspective. 
Our anticipations are ethico-politically motivated narratives about the future, systematically grounded on causal and structural analysis, but enmeshed in pragmatic and normative considerations and discussions. I conclude by outlining how the social scientific notion of reflexive, holistic and future-oriented self-regulation of social systems has interesting parallels in the theory of history, ethics and politics of the dialectical phase of CR (Bhaskar 1993; 1994). Through human emancipation, our temporality changes; we learn to relate to the future in new and more reflexive ways.

\section{Causation in critical realism from a pragmatic and action-oriented point of view}

Let me start by summarising the basic CR view of causation, illuminating the implicit and explicit pragmatic aspects of realist causal analysis. In his seminal work A Realist Theory of Science, Bhaskar (1975/1997: 240) argued that science 'has enormously increased our powers of intervention in and control over, as we say, "the course of nature"”. Because science has been so successful in practical terms - it works - it is a good place to start a philosophical analysis of the presuppositions of our historical practices. What are the conditions of possibility of scientific practices?

What must the world be like for laboratory experiments to make sense? As is well-known, Bhaskar's answer was that the scientists must be creating an artificial closure by their own labour and that a closure facilitates revealing the mechanisms of nature. Outside laboratory circumstances, causal effects are occurring only in open systems, where strictly regular law-like conjunctions are diffic ult to find. This necessitates the key distinction between causes/mechanisms/laws, on the one hand, and empirical regularities, on the other hand. Causal mechanisms are transfactually efficacious across contexts, but their precise effects in open systems are always context-dependent (being contingent upon what other mechanisms are at play, etc.).

In all his books, Bhaskar insisted that causal structures and mechanisms can exist and act not only where (i) no empirical regularities prevail but also (ii) where no human perception occurs. We 
are dependent on, and part of, the cosmos, but the cosmos has evolved and exists quite independently of us humans. Causation cannot be reduced to the human perception of it. Thus Bhaskar (1975/1997: $5,24,34-35,48,148)$ criticised in strong words various forms of empiricism for their anthropocentrism. Sometimes Bhaskar tended to take his criticism of other philosophical positions a bit too far, however. Consider, for instance, his puzzlingly critical and, simultaneously, approving discussion of John L. Mackie's (1974) famous account of cause as an INUS condition (an insufficient but non-redundant part of an unnecessary but sufficient condition).

While recognising the importance of the pragmatic context of picking out a particular factor or thing as the main cause of a particular outcome, Bhaskar nonetheless claimed that the choice was not up to the researcher to make:

By contrast, non-anthropomorphic generative analyses can immediately explain why it is that we pick out the particular factor that, in the pragmatic context of our concerns, we do: namely, because it is the factor which, in the real context of the genesis of the event, made the difference, tipped the balance, produced the outcome. (Bhaskar 1979: 207, n. 23)

Mackie's standard example concerns a fire that has partly destroyed a house. Experts conclude that the fire was caused by an electrical short-circuit within the house. A number of other INUS conditions were involved in generating the fire, such as the presence of flammable material and oxygen, and the absence of adequate sprinklers.

What we single out as the cause depends largely on our practical capacities and expectations of normality. For instance, the presence of the oxygen, too, can be seen as the cause of the fire, say in a laboratory or in a factory, where special precautions are taken to exclude oxygen (Mackie 1974: 119). All INUS conditions are real and implicate real powers (structured entities with the power or tendency to manifest particular characteristic properties $\mathrm{X}$ and produce outcomes $\mathrm{O}$ ). Indeed, what makes the relevant difference depends very much on the pragmatic context. ${ }^{4}$ 
The main reason why we should nonetheless follow Bhaskar, to a degree, in stressing the importance of 'the real context of the genesis of the event' is largely ethical. As Rom Harré (1986: 89) has explained, if we read the realist manifesto 'Scientific statements should be taken as true or false by virtue of the way the world is' as an ethical principle it would run something like this: 'As scientists, that is members of a certain community, we should apportion our willingness or reluctance to accept a claim as worthy to be included in the corpus of scientific knowledge to the extent that we sincerely think it somehow reflects the way the world is'. A false claim can be useful for some (legitimate or illegitimate) purpose. Truth cannot be reduced to usefulness but constitutes a higher virtue. Thus the realist perspective inspires the openness of mind and a movement towards deeper levels: from those things that we can readily see or use towards postulating new deeper-level entities and processes.

To sum up, the identification of particular causes is characteristically based on pragmatic considerations, even when the real causal powers are quite independent of us humans. The technical aspect of science represents only a limited, partial and historically restricted human interest (Bhaskar 1986: 229), but this aspect is nonetheless important. Since practical manipulation of reality is possible only if there is some stability in the world (Woodward 2003), this admission would seem to imply at least some predictability. Yet, practical adequacy in this sense is not the only consideration. Critical scientific realism stresses the role of truth and reality, also for ethical and emancipatory reasons. The point of science is to maximise our capacity to learn, also by way of proceeding towards deeper layers of reality. What must be taken into account as well, both in our explanations and anticipations, is that change tends to be ubiquitous at higher levels of emergence and complexity. ${ }^{5}$

\section{On rational expectations about the future}

The openness of natural and/or social systems does not exclude the regularity of at least some things and connections. The pragmatic and technical aspect of science requires a fair degree of predictability. 
Moreover, all knowledge must be practically adequate at least to some degree for our everyday activities to be possible. All knowledge 'must generate [some] expectations about the world and about the results of our actions which are actually realized' (Sayer 1992: 69).

Over time, Bhaskar tacitly revised his claims in this regard. In his early and best-known works, Bhaskar emphasised the radical asymmetry between explanation and prediction (Bhaskar 1975/1997: 127; 1979: 142). Over time, however, his language softened. In Scientific Realism and Human Emancipation (1986: 218), Bhaskar substituted categorial asymmetry for radical asymmetry. The past and the future belong to different causal and temporal categories. The future is real but not yet determined. Bhaskar explained that well-grounded prospective explanations are rare 'because we do not know which out of a myriad of possible sets of circumstances will actually materialise' (1986: 218-19). This new formulation means, however, that well-grounded explanatory anticipations are in principle possible; and it also raises the question of precisely how well-grounded our anticipations must be. In Dialectic (1993: 142-44), Bhaskar went on to argue that future is an increasingly shaped and structured possibility of becoming, mediated by the presence of the past:

The future is paradigmatically shaped possibility of becoming [that, as a possibility] may be closer or more distant from us, more or less about, and more or less likely to be actualized.

This passage introduces new considerations concerning future possibilities: their distance, aboutness and probability. From the 1990s onwards, many critical realists have started to reconsider the possibility of rational anticipations from this or related angle. For instance, Berth Danermark et al. (2002: 68, first published in Swedish in 1997) introduced the notion of 'pseudo-closed system'. Many social organisations have causal powers to arrange social activities in a manner that generates some closure and thus also regularity, predictability and control. These powers can be used for anything from coordination of actions to manipulation of subjects. This closure is not similar to the one achieved in laboratory experiments, it is of a 'spurious kind', but nonetheless implies some predictability, although change is a constitutive characteristic of human societies. 
Tony Lawson (1997: 204-13) introduced, in the field of economics, the concept of 'contrastive demi-regularity', similarly indicating the existence of partial closures in society. Contrastive demiregularities are about contrasts between categories or spacetime areas and are expressed in terms of regularities within a given range of variation with certain probability. They are not strict but probabilistic regularities, limited to a particular spacetime area, and liable to change. The identification of demi-regularities (or demi-regs) is not an aim in itself; rather, it is the task of social scientists to move quickly from identifying them towards analysing the deeper social structures and causal complexes generating these manifest phenomena.

Nonetheless, Lawson argues that the initiation of much social scientific research depends upon the detection of contrastive social demi-regs. He (1997: 206-207) gives a number of examples of demi-regs, for instance: 'women look after children more often than men do'; 'a relatively small proportion of children from poor backgrounds in the UK continue into higher education'; 'average unemployment rates in western industrial countries are higher in the 1990s than the 1960s', and so on. In IR, the democratic peace hypothesis is a contrastive demi-reg: 'since the late $19^{\text {th }}$ century, democratic states fight much less (if at all) with each other than do other dyads of states'. Demi-regs require explanation; they are not in themselves explanations.

Petter Næss (2004: 150) has further criticised the standard CR rejection of the possibility of (any) meaningful predictions on the pragmatic grounds that some planning must be possible. Næss argues that regression analysis 'may hint at possible causal relationships that may subsequently be explained by theoretical reasoning and qualitative empirical research', and that certain qualitative and rudimentary predictions concerning the aggregate level effects of particular policies and measures must be, and are, possible. In a parallel fashion, Pertti Töttö (2004) has disputed the (early) Bhaskarian dichotomy between open and closed systems, making a reasonable point that almost all systems including our solar system, the object of Newton's mechanical theories, often given as the main example of a natural closure - are in fact situated somewhere between absolutely open and absolutely closed systems, i.e. they are closed to a varying degree. We should, therefore, expect to find some 
demi-regs or demi-regular schemes of development and rhythmics in society (patterns of flow, cycles, ratchets, spirals, etc.). Openness is a matter of degree.

Predictability is limited, of course. CR explains why the actual is only a part of the real world, which also consists of non-actualised possibilities and unexercised powers of the already existing structures and mechanisms that are transfactually efficacious in relatively open/closed systems. Furthermore, emergence is also real. It is possible that new powers, structures and mechanis ms emerge, and the existing ones may disappear. ${ }^{6}$ While particular geo-historical powers, structures and mechanisms may generate some predictability via social organisation and/or via uninte nded consequences of multiple actions in social systems, and while higher strata of social organisation can also use knowledge about lower-level demi-regs in achieving further predictability, or in making some planning possible, things can and do change.

These limitations to predictability notwithstanding, the various degrees and levels of closure that we can find in society co-enable systematic futures studies. I have argued (Patomäki 2006) that, like a historian, a futurologist (i) explains the development of various conjunctures and compounds; (ii) specifies boundary conditions for the existence and transfactual efficacy of particular social agents, structures and mechanisms; and (iii) develops a geo-historical narrative up to a relevant point. Historical analogies, too, can be illuminative when they are rooted in the identification of similarities in underlying causal structures and processes across space and time.

Given relative closures at different levels of social organization and systems, many things are connected in a regular fashion, and social systems exhibit some, even if only limited, predictability. Regularities generated by social systems can be brought about by homeostatic causal loops (often somewhat blindly, as in the reproduction of class structure via the educational system), self-regulation through feedback (often quasi-mechanically, as in markets) and reflexive self-regulation (deliberately, for instance through budgets and laws or targeted activities such as social work). Future is real but not yet determined and thus consists of a multiplicity of different possibilities. It unfolds 
through various transformative events and nodal points, themselves presupposing particular conceptand action-dependent structures. Geo-historical processes can be self-attenuating or self-reinforcing.

\section{Historical analogies, explanatory models and scenarios about possible futures}

So far, I have argued that social systems exhibit some, even if only limited, predictability, as recognised by a growing number of critical realists. Historical analogy and scenarios are methodological tools to actualise the possibility of anticipating possible and likely futures in a rational manner. The immediate objection is that history never repeats itself. Can we really learn from history? We know that simple horizontal historical analogies, often staying at the rather superficial level of one-sided interpretation of actual events, such as 'Munich 1938' or 'Cuba 1958/59', have almost invariably misguided the decision-makers (Khong 1992: 7).

Temporal social contexts - even when the relevant powers, structures and mechanisms endure across contexts - are always different in some regard. Action, by definition, involves the possibility of doing otherwise; and powers, structures and mechanisms tend to change, sometimes slightly, in some cases thoroughly. Occasionally, a small difference can suffice to make a big difference in outcome (processes can be non-linear). However much the contemporary geo-historical context may resemble the period from 1871 to 1914 , or the 1920 s and early 1930 s, there will be no simple replication of the First World War or the rise of Mussolini and Hitler.

Nonetheless, there can be processes and tendencies that are similar in some ways. Historical analogies are only partial; and they idealise and abstract from their source. A historical analogy is best viewed as a candidate for illuminating some essential characteristics of the geo-historically evolving whole under study. In each case, something more is needed to fully understand the relevant whole. A good explanatory model must rely on a variety of historical and theoretical sources, as do scenarios about possible futures built on them. Over-reliance on one source can be misleading and problematical. This is especially true for historical analogies. 
Social scientific research, therefore, starts with a broadly pluralist set of interesting candidates for a plausible explanation. It eliminates and refines them step by step until only a contracted range of fully endorsed iconic models is left. This is the reductive approach to model-building (Rescher 1987: 33-34) Analogies are based on some similarities between (i) properties or outcomes of a known case and (ii) less familiar explanandum. However, historical analogies are always complex and open to different interpretations. If the eras are in some important regards dissimilar, we need to know whether another characteristic or outcome of the first era is also likely to belong to the contemporary era. In every historical analogy, there are both horizontal and vertical relations. Horizontal relations concern similarities and differences between the historical eras at the level of actual events, trends and developments, while vertical relations concern relevant causal mechanisms and processes within them (as well as the possible causal connections between them) (see Hesse 1966: 58-64).

In establishing the degree of validity of an analogy, it is essential to study especially vertical relations by building explanatory models of the structural underpinnings of significant similar/contrastive processes, trends or outcomes in both eras. A historical analogy is claiming some but not all essential similarities. There are idealisations and there are abstractions. A pure idealisation has all the relevant characteristics of its source subject, but at least some of them are, according to some scale of value, more perfect than the source subjects' properties. Abstraction simplifies. If the

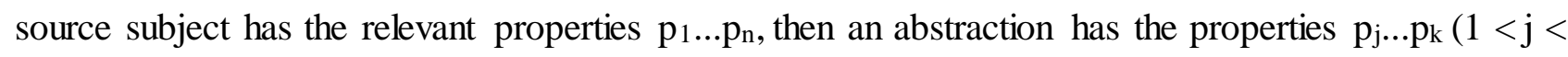
$\mathrm{k}<\mathrm{n}$ ); that is, fewer than its source subject (Harré 1970: 41-42).

Max Weber's ideal types are a case in point. For Weber, ideal types offer an ideal picture of events, types of action, and social relationships, by an 'analytical accentuation' of certain elements of reality. In more dialectical terms, one can also talk about abstraction as isolation in thought of a one-sided or partial aspect of an object. It is important to keep in mind what we abstract from, and whether or not the abstraction preserves the essential properties of the object (Sayer 1992: 86-87). A practical judgement about this requires detailed knowledge about the substance and relies on various epistemic criteria. All practical judgements are fallible. 
Historical analogies and structural explanations can be used to build scenarios about possible futures. Scenario is a description of what could possibly happen. Scenarios as such are not predictions. They start with an analysis of the existing structures and processes and their inherent possibilities, coupled with the assumption that futures remain open until a particular possibility is actualised. Scenarios can utilise information about contrastive demi-regs (including various trends) but presuppose qualitative knowledge about natural mechanisms, social contexts, causal complexes, and links between the different processes that together account for world history.

\section{An example of historical analogy and related scenarios}

To give a focal example, consider the possibility that the contemporary era may be in some important regards similar to the era of 1870-1914 (Patomäki 2008). Before 1914, the world economy was in many dimensions as highly integrated as it is today. Some institutional arrangements, such as the euro, have effects similar to those of the Gold Standard, which prevailed until 1914. Moreover, the combination of policies of free trade and free movement of capital is similar to the regime that existed before World War I. There are several further and quite remarkable resemblances: rising inequalities, rising nationalism, financialisation and the resulting dominance of finance, turn to quasi-imperial practices, and return of geopolitics. This list, which can be extended, constitutes a prima facie case for a partial historical analogy.

Although there are also differences between the two eras, various vertical similarities further ground the analogy, including: mechanisms and processes of uneven, contradictory growth; mechanisms leading to the accumulation of wealth in relatively few hands; the related processes of de-democratisation; and the tendency of finance to generate booms and busts. As only limited aspects of historical processes may prove sufficiently similar to provide insights into future possibilities, the point is not to look only for in some ways similar episodes or trends, but to focus on comparable structural liabilities and tendencies. These may give rise to in some ways analogical outcomes, albeit 
in a non-deterministic way. What is especially needed is a causal analysis of the currently existing structures and on-going processes, upon which scenarios of possible futures can be built.

The main purpose of a partial historical analogy is to illuminate, with other relevant understandings of the situation, ethico-political choices and their likely future consequences. The point of explanation is thus pragmatic and future-oriented (cf. Jackson 2016). This future orientation can be explicated in terms of scenarios, i.e. narratives of possible and likely developments. The three world-historical scenarios $\{\mathrm{A}, \mathrm{B}, \mathrm{C}\}$ and their sub-scenarios $\mathrm{I}$ have proposed on the basis of the analogy between 1871-1914 and the current era (Patomäki 2008: Chapters 7 and 8) are not mutually exclusive, but they do differ in the ways they envisage the main dynamics of the $21^{\text {st }}$ century history.

Scenarios A are concerned with the contemporary short- to mid-term future politico-economic competition among great powers that is, to a certain extent, analogous to the developments that led to the Great War. Neo-liberalisation has meant a partial return to the past in terms of how capitalist market economy works within countries and through the dynamics of the world economy as a whole. Some of the $21^{\text {st }}$ century political economy contradictions are analogous to those of the pre-1914 era, often stemming from insufficient aggregate demand and attempts to export problems to other countries. Scenarios A are also based on an analysis of the consequences of neo-liberalisation as a self-reinforcing process, involving consequent securitisation and related culturally based processes of enemy-constructions.

Scenarios B focus on the possibilities for emancipatory transformations towards something that may be called green-democratic global Keynesianism (seen as a transient state of world history and global governance). Scenarios B analyse the dialectics between limited-scale future wars and economic crises, and the possible rise of transformative actors that could respond to the problems and contradictions of the global political economy in terms of collective learning, and by building new democratic global-Keynesian institutions. Finally, scenarios $\mathrm{C}$ spell out the transformative implications of possible nuclear and climate catastrophes. 


\section{Assessing and revising the probability of scenarios}

Which of these three main scenarios is happening, if any? How likely are they? To further guide our practical reflections and actions, we also need to explicate the meaning of the concept of probability. Arguably the main meaning of probability is practical. If something is probable, it constitutes an approvable basis for action and choices. The concept of probability also implies that chance, in some sense, is involved in bringing about a particular outcome (Bartholomew 2008: 17-27). We should thus first distinguish between epistemological and ontological chance.

Epistemological chance concerns uncertainty and ignorance. We may know some relevant things but not enough to be sure about what is going to happen. As more knowledge about the relevant mechanisms and processes becomes available, the uncertainty of our anticipation should decrease. This is not always the case, however. In his early work, Keynes (1920/2008) argued that probability concerns an inference from evidence/reasons to our probability-judgements. The weight of evidence does not necessarily change our probability estimate but may also alter our confidence in it. Learning more about the situation can mean that our sense of ignorance increases, implying that the weight of evidence and our confidence in it may in fact decrease.

Complete knowledge may be practically unobtainable and thus uncertainty is non-redundant as a matter of principle. Furthermore, in open systems, relative frequencies cannot be more stable than contrastive demi-regs. In open systems, two or more (relatively) independent causal chains can coincide in a manner that is fully unpredictable; and intrinsic qualitative changes are possible as well. This comes close to the ontological meaning of chance. Pure chance occurs when there is nothing at all that has any predictive value. ${ }^{7}$ In practice, it is impossible to draw a watertight line between ignorance and pure chance, as there may always be a factor that has gone unnoticed. On the other hand, it is also important to underline that what is unpredictable at the scale or level $\mathrm{N}$ may appear quite law-like and predictable in probabilistic terms at the scale or level $\mathrm{N}+1$ or $\mathrm{N}+\mathrm{i}(\mathrm{i}>1)$. Also, human choices are free and unpredictable as a matter of principle, yet involve rule-following, 
dispositions, social expectations and other things that have predictive value and can form relatively regular patterns at a higher level of aggregation, complexity or organisation. Perspective and scale do matter.

When studying large-scale (perhaps truly global) social systems and their possible futures, we can safely assume that both epistemological chance (uncertainty, ignorance, and the related lack of confidence) and ontological chance (accidents, independent processes coinciding, pure chance) are involved. Point-predictions are therefore impossible. Even probabilistic interval predictions can at best specify the generic type of event or process that will happen within a particular time-space-frame. The more precise the prediction is, however, the easier it is to falsify. This is important because scholar-partisans use all kinds of means to fortify their positions against falsification. As Philip Tetlock (2015: 4) argues:

Without retreating into full-blown relativism, we need to recognize that political belief systems are at continual risk of evolving into self-perpetuating worldviews, with their own self-serving criteria for judging judgment and keeping score, their own stocks of favorite historical analogies, and their own pantheons of heroes and villains.

This is not all, however. The problem is deeper still. The openness of social systems means that social beings and relations can change qualitatively. After a prediction is made, in principle anything in society - agents, rules, resources, practices, structures and mechanisms - can change. Often, societal changes happen quite independently of the prediction, posing nevertheless additional difficulties for anyone trying to predict the future. A deeper complication is that social sciences are internally related to their subject-matter. By learning about a prediction, actors can change their behaviour. Predictions can become self-fulfilling or self-defeating; they may even instigate institutional transformations (for example, ecological warnings prompting political activities that lead to the establishment of environmental ministries and international treaties and organisations). From a pragmatic point of view, this reflexive involvement of predictions can be viewed as the chief reason 
why we need them. Knowledge and the social world are intradependent. It is not only that anticipations can be self-fulfilling or self-denying; oftentimes, this is their very purpose.

All this suggests two somewhat contradictory criteria for an adequate prediction: relevance and accuracy, on the one hand, and success in informing practical actions and shaping the world, on the other hand. One implication is that many predictions can only be tested - falsified - by means of counterfactual reasoning. ${ }^{8}$ What would have happened, had $\mathrm{X}$ been otherwise? $\mathrm{X}$ may denote reflexive phenomena such as predictions, but also accidents, coincidences and pure chance play a role in necessitating counterfactual reasoning. Although it is true that all causal analysis involves counterfactual reasoning ('had $\mathrm{X}$ been otherwise, would $\mathrm{Y}$ have occurred?'), reflexivity and ontological chance introduce a further non-testable element into social sciences, making ex post falsification of predictions arduous. This reflects and further complicates the general methodological problem of studying open systems. In the absence of closure, decisive tests between theories are hard to come by. Ideological positions evolve easily and tend to fortify themselves rapidly. ${ }^{9}$

Large-scale scenarios are often composites of multiple probability-judgements and conditional, reflexive predictions. In the absence of simple technical procedures to test any of these or the underlying theories, their rationality depends largely on whether the ethical guidelines of realist research are being followed. The more open we as researchers are to counterarguments, counterevidence and learning, the better; the more precise we make our claims and predictions, the easier their falsification and thus learning. This accords with the ethics of the scientific realist manifesto: 'Scientific statements should be taken as true or false by virtue of the way the world is.' Truth as a metaphor of correspondence has conduct-guiding force. ${ }^{10}$

The good news is that while decisive falsification is often hard to achieve, it is possible to rationally revise our probability estimates also ex ante, both in relation to new evidence concerning the past and new world historical events and processes. For this we can use the Bayesian theorem, either literally (when we have numerical probability values) or metaphorically (normally, i.e. when we have only ordinal probability orders, based on intersubjective judgements about the weight of 
available quantitative and qualitative evidence). The Bayesian theorem concerns a part-whole relationship. ${ }^{11}$ The key idea is that empirical research is an iterative process through which a new understanding of a whole emerges on the basis of openness to evidence and of gradually revising previous understandings. For example, if an original probability is very low, the Bayesian theorem implies that a single contrary occurrence does not necessarily increase probability even to a noticeable chance; but even in the case of a very low original probability, many like occurrences should have a cumulative effect of making a difference to our estimation of probabilities. (For more detailed discussion, see Patomäki 2010a: 154-61).

When assessing the probability of a scenario, many relevant observations become available only in the course of history. A key problem is, of course, that we do not usually have numerical values for the original probabilities. Furthermore, the new observations tend to be theory-laden descriptions of geo-historical events and processes rather than systematic quantifiable data. And yet, somehow the occurrence of these events and turns should slide the estimated probability in the direction of the occurrence in accordance with the basic intuition of the Bayesian theorem. The theorem helps to analyse the impact of an occurrence of something by decomposing the problem into smaller parts even when we do not have any numerical values.

To continue the above example of three scenarios $\{\mathrm{A}, \mathrm{B}, \mathrm{C}\}$, arguably the election of Barack Obama as the President of the US, and the global financial crisis of 2008/2009, have further (slightly) increased the likelihood of scenarios A (vis-à-vis scenarios B and C) and thus the relevance of the historical analogy to the era of 1870-1914. Obama has not made much of a difference in either way and the responses to financial and economic crisis have not involved attempts to build more sustainable common institutions, but have remained national and contradictory, while further strengthening the self-reinforcing process of neo-liberalisation (about the positive feedback loops via the mechanisms of learning, power and institutionalisation, see Patomäki 2008: 128-55). The world seems geared towards a path that makes a global military catastrophe progressively more likely. ${ }^{12}$ 
When read as a prediction, this claim should be made more precise; but the point is also to shape history by warning about a dire possibility that is intrinsic to the ongoing processes.

\section{Conclusions: reflexive self-regulation of social systems and the pulse of freedom}

The point is not to try to reduce theory to the practical knowledge of state-leaders, diplomats, international civil servants and the like. What I have argued instead is that good theory should be practically adequate in the generic sense that it can inform diverse political practices by generating expectations about the world and about the results of our actions. In principle, we can let anticipated futures evolve more or less on their own or may advance them actively; alternatively, we can try to override the tendencies towards these anticipated futures, whenever there are good reasons for doing so. This is a primary ethical and political choice.

I agree with Stefano Guzzini (2013: 530-38) that knowledge can move towards higher orders of reflexivity. By showing why there are no stable and uncontested empirical invariances, CR pushes both theoreticians and practitioners to critically reflect upon the conception of causation they have so far taken for granted. If there are no stable empirical regularities in open systems, then there can be no decisive tests between theories either. Rationality and openness to learning become ethical matters. Technical methods or interpretative readings of history or texts provide no firm grounds for knowledge. Rather, they are, at best, possible sources of counterevidence and counterarguments, encouraging revisions and enabling learning.

The concept of cause is a metaphorical abstraction. Causation comes in different forms. It does not follow that causation is unreal. Nothing happens without being caused. The problem is that causation has typically been misunderstood by positivists and post-positivists alike. Causation works transfactually in open systems, i.e. as tendencies that may or may not bring about a given outcome, depending on the way different causal chains and processes coincide, coalesce and interact. Causation is irreversible but unending; the future is real but not yet fully determined. 
The early CR thesis of radical asymmetry between explanation and prediction does not hold. The present is a moment of becoming, and makes reference - and is relative - to one or more ongoing processes. Most intertwined spatiotemporal processes are continuous across any given present. The future is also present in the moment of action, centred as it is on anticipating the future, whether implicitly or explicitly. We can and also do have systematic knowledge about various commitments, agreements, institutional arrangements and other ways of binding the social future. Moreover, as social scientists, we recognise that contrastive demi-regs and explanatory theories and models can have predictive value, too. If we understand the past and the present, we have many clues about the ways in which the future is already unfolding.

Obviously explanation and prediction are not fully symmetrical either. Any present moment is open-ended: the properties of the actions and events happening 'now' depend, in part, on the processes that are gradually unfolding over time. In addition to the limits posed by epistemological chance, there are also ontological reasons why the future must remain open-ended at all relevant scales of time and space. In open systems, accidents, coincidences and pure chance are real phenomena. At the social/psychological level of reality, also reflexive predictions and human freedom play a role. Moreover, whereas structures generate transfactual tendencies, structures themselves are liable to changes. New forms of emergence and complexity are often unpredictable, for it is difficult to anticipate what has not yet been put together, invented or created. In these senses, world history is open-ended.

Guzzini (2013) stresses that knowledge can move towards higher orders of reflexivity. Reflexivity means the capacity of actors to reflect - in consciousness and discourse - on their own conditions and place, accepting that both can change and perhaps be changed. Reflexivity in the social sense turns on the internality of social science with respect to its subject-matter. Social scientific knowledge contributes to reflexive self-regulation. Reflexive self-regulation arises when knowledge about the way the social system functions is applied recursively in interventions that aim at avoiding unwanted or achieving desired outcomes. Arguably, when self-regulation is becoming increasingly 
reflexive, holistic and future-oriented, the very temporality of human existence is being transformed. By shaping the future, actors are also changing the present, the meaning of the past, and the processes constitutive of their beingness.

These ideas come close to Bhaskar's $(1993 ; 1994)$ dialectical CR and its idea of freedom. Dialectic is, formally, about the absenting of absence. Various ills - anything causally efficacious that is not good - can be seen as constraints. Many ills as constraints, and thus as absences, can be absented over time. Less constraints means more freedom. Dialectic is about the onto-logic of change in the human sphere and, in some measure, in the biosphere as a whole. This onto-logic of change can also be conceived as the ground for various geo-historical processes of expanding freedom. In this normatively oriented theory of world history, agency is understood in terms of transformative praxis, which itself is bound to be transformed over time, following the same logic of intrinsic qualitative changes. Agency is oriented to rationally groundable projects. Autonomy as selfdetermination, including the freedom of choice, is always a matter of degree, but has been and can be enlarged.

The degree of freedom can be increased by replacing particular unnecessary and often misrepresented causal sources of determination with more wanted, needed and also more clearly evident sources of causal determination, classically implying attempts to increase one's autonomy as self-determination. Despite the fundamental open-endedness of world history, Bhaskar argues further that there is a rational tendential directionality of history towards an increasing self-determining democratic control over the history of humankind, on this planet and perhaps elsewhere.

I take this to mean that the future is in the process of coming to be increasingly (co-)determined by our normative discourse about its desirability, informed by adequate and plausible scenarios about possible and likely futures. Both increasing reflexivity and the notion that our temporality is likely to be changing are compatible with this emancipatory idea. Yet, the tendential rational directionality does not mean that actual world history would always be going into that direction, no matter what 
scales of time we are talking about (say 10, 100 or 1000 years). The actual direction of world history depends also on what we do, apart from many other contingencies.

\section{Notes}

1 See also the 2014 ISQ Symposium 'The "Third Debate" 25 Years Later', edited by Patrick Thaddeus Jackson, which includes Lapid's own reflections. While Lapid continues to find reasons to be optimistic about IR developments, Yale H. Ferguson and Richard W. Mansbach capture the prevailing state of the field of IR more realistically:

The 'Third Debate' did not alter the views of the field's positivists who continue to dominate many leading departments and journals especially in the United States, although thankfully far less so in Europe. [...] [O]ne unintended and rather pitiful result of the Third Debate has been a proliferation of incommensurable post-positivist islands. Quite apart from the gate-keeper empiricists, we have subsequently moved from belated tolerance of diversity to an attitude of 'anything goes'. [...] And one unfortunate result of the Third Debate was to foster some perspectives that reflect thinly veiled ideological posturing rather than a genuine search for understanding. Worse, we believe, some are even less substantial than that.

One implication is that for both the positivist mainstream and a number of those incommensurable post-positivist islands, CR and its main arguments about ontology and causation remain unfamiliar. The symposium is available at http://www.isanet.org/Publications/ISQ/Posts/ID/304/25-Years-after-The-Third-Debate-Twopianissimo-bravos-for-IR-Theory.

2 In its generic meaning - including many common sense versions of pragmatism - the term pragmatism refers to a mindset that sees thought as an instrument or tool for prediction, problem solving and action, rather than as a neutral vehicle for abstract un-interested representation of 
reality (or for 'mirroring reality'). In philosophy, the term is first and foremost associated with the American philosophers of the late nineteenth and early twentieth centuries such Charles Sanders Peirce, William James, John Dewey and George Herbert Mead. To a certain degree, it is also associated with Richard Rorty, especially with his later postmodernist writings from 1979 onwards (criticised heavily by Bhaskar 1991). For discussions on pragmatism and IR, see e.g. Cochran (2002) and Bauer and Brighi (2011). Käpylä and Mikkola (2011) attempt to criticise CR from a Rortyan position and Hamati-Ataya (2012) claims that Morton Kaplan's pragmatism can transcend the antagonism between positivism and post-positivism better than CR.

3 In the works of Rom Harré $(1970 ; 1979)$ and Andrew Sayer $(1992 ; 2000 ; 2011)$ as well as in my own works (Patomäki 1992; 2002; 2010a), the practical and political aspects of realist causal explanations are more explicit and depicted in more positive light.

4 Whether it was short-circuit or the presence of oxygen that caused the fire, the first answer raises further questions. What, then, caused the short-circuit? Perhaps a faulty mechanism, or some sort of human error? The line of posing further questions may lead to attributing moral or legal responsibility to someone; or may be related to, say, insurance claims; or may aim at improving (regulations concerning) the way electrical systems are constructed in houses. For further discussion on this theme, see also Humphreys 2016.

5 An emergent property is one that is not possessed by any of the parts individually and that would not be possessed by the full set of parts in the absence of a structuring set of relations between them. There is a hierarchy of levels of organisational complexity from the strictly physical to the chemical and biological and finally to the social/psychological level. The social/psychological level is liable to rapid changes - much more rapid than at the biological level - involving also further and new forms of emergence. See Elder-Vass (2010: 16-20 et passim).

6 See note 6 above.

7 The early CR claim about a radical asymmetry between explanation and prediction amounts to saying that there is never anything of predictive value. In any context, there are always numerous 
possible relevant causal forces, mechanisms and processes, perhaps existing at different levels of reality; and all of them are equally likely to contribute to the outcome. Therefore, only (theoretical) and historical explanations are possible, and they must be conjunctural and retrodictive in their form. For instance, a flu epidemics spread in Moscow at the time when power struggle in the Communist Party of the Soviet Union was about to reach its climax. Trotsky could not make the decisive meeting of the Politburo in late 1923 because he was ill, and Stalin seized the opportunity. Two causal chains coincided in an unpredictable way. We can trace coinciding causal processes backwards, but not forward (see e.g. Bhaskar 1979: 142). However, in a footnote, Bhaskar introduces a distinction between 'theories which are explanatory but non-predictive (such as Darwin's, Marx's or Freud's) and generalisations (for example, about capital-output ratios or suicide rates) which may be accurate predictors but are totally nonexplanatory' (ibid.:178, n. 20). This is a step forward, but again the distinction is too categorical. Contrastive demi-regularities can be explained, too. Thus, explanatory theories in social sciences can have predictive value. Also vertical relations of analogies are grounded on this possibility.

8 The logic of counterfactuals is: 'if $p$ then q', when $p$ is not true. From the point of view of modal logic, there is no difference between counterfactuals and scenarios, except tense. Counterfactuals are about the past, scenarios about the future. They both operate with the concepts of necessary, possible, compossible, incompossible, contingent, plausible and probable. The evidence for assessing the plausibility and probability of different scenarios can only come, directly or indirectly, from the study of the past and present society. Analysis of these concepts and connections must be left to another paper, but the modal-logical similarity between counterfactuals and scenarios is nicely explicated by Booth and Rowlinson (2009). For a discussion on the concepts of compossible and incompossible, see Jones and Jessop (2010).

9 From this point of view, Bhaskar (1979: 144) analyses the consequences of the continuing hegemony of positivism. Because of the absence of decisive test situations, coupled with continuing one-sided allegiance to a mere predictive rather than explanatory and other criteria, the 
methodology on which one's research relies gets mystified; entrenched or otherwise privile ged theory is protected; alternatives are stunt; and/or there is an encouragement of (a belief in) the unresolvability of theoretical conflicts - which, in practice, means their resolution in favour of the status quo. This explains quite nicely the current state of IR. While positivist methodologies are mystified, especially in the US, post-positivist alternatives are allowed to co-exist even in the US, while in Europe they are dominant in many places. Yet, in effect, in their practices, these 'incommensurable' post-positivist islands tend to underpin the status quo; $c f$. note 1.

10 It should be noted that in many science contexts, too, testing and falsification occur in open systems. Consider the case of epigenetics. Epigenetics is a heterogeneous field that focuses on non-genetic inheritance phenomena, comprising all meiotically and mitotically heritable changes in gene expression that are not coded in the DNA sequence itself. The real challenge is to combine the DNA and the epigenetic part of inheritance with the statistical explanations of ecologists. The test criteria typically involve multiply conditioned manipulations and observations of their effects; particularly checking whether effects remain invariant under a range of interventions. Researchers often know that an effect occurs without knowing why (no mechanism can be specified). For an illuminating discussion about the methodological difficulties of causal analysis in the context of epigenetics, see Baedke (2012). Analogically, also social scientists have to combine theoretical models, geo-historical comparisons, trends and other demi-regs, thought-experiments, counterfactual reasoning, etc. to account for a variety of possible interventions and circumstances and to identify relevant structures, mechanisms, fields etc. (for an imaginative account of how to test claims, see Alker 1996).

11 The basic idea is that we have a prior probability ratio for two hypotheses (that may describe something happening in the future) and then we have actual new evidence that seem to indicate a different likelihood ratio. We aim at maximum likelihood, but take into account the prior probability ratio in our probability-judgements. The result is supposed to be a balanced judgement. A bit more technically, the theorem says that a conditional probability for event or development $\mathrm{B}$ 
given event or development $\mathrm{A}$ is equal to the conditional probability of $\mathrm{A}$ given $\mathrm{B}$ multiplied by the marginal probability of $\mathrm{B}$ and divided by the marginal probability for A (the sum of the conditional probability of $A$ under all possible event $B_{i}$ in the sample space). For basic texts on Bayesian statistics, see for example Bolstad (2004) and Lynch (2007).

12 Since the global financial crisis and Obama's election and first couple of years as the President of the US, further developments have reinforced this path, including the Euro crisis (as the second phase of the global crisis); the development of a new cycle of boom and (the foreseeable) bust in the global financial markets; failed attempts at democratisation and other maldevelopments in the Middle East; arms race in East Asia; and the conflict in Ukraine. For an argument that the continuous concentration of capital and the rising importance of past and inherited wealth in the sense of Piketty (2014) increase the likelihood of a major economic and political disaster, see Patomäki (2014). 


\section{References}

Alker, Hayward (1996) Rediscoveries and Reformulations. Humanist Methodologies for International Studies, Cambridge: Cambridge University Press.

Baedke, Jan (2012) 'Causal Explanation Beyond the Gene: Manipulation and Causality in Epigenetics', Theoria. An International Journal for Theory, History and Foundations of Science 27(2): 153-74.

Barkawi, Tarak (2015) 'Scientific Decay', International Studies Quarterly, article first published online 26 May, 2015, doi: 10.1111/isqu.12204.

Bartholomew, David J. (2008) God, Change and Purpose. Can GodHave It Both Ways?, Cambridge: Cambridge University Press.

Bauer, Harry and Elisabetta Brighi, eds (2011) Pragmatism in International Relations, London and New York: Routledge.

Bhaskar, Roy (1975/1997) A Realist Theory of Science, London: Verso.

Bhaskar, Roy (1979) The Possibility of Naturalism: A Philosophical Critique of Contemporary Human Sciences, Brighton: Harvester Press.

Bhaskar, Roy (1986) Scientific Realism and Human Emancipation, London: Verso.

Bhaskar, Roy (1989) Reclaiming Reality. A Critical Introduction to Contemporary Philosophy, London: Verso.

Bhaskar, Roy (1991) Philosophy and the Idea of Freedom, Oxford: Blackwell.

Bhaskar, Roy (1993) Dialectic. The Pulse of Freedom, London: Verso.

Bhaskar, Roy (1994) Plato Etc. The Problems of Philosophy and Their Resolution, London: Verso.

Bolstad, William M. (2004). Introduction to Bayesian Statistics, Hoboken, NJ: Wiley-Interscience.

Booth, Charles and Michael Rowlinson (2009) 'Scenarios and Counterfactuals as Modal Narratives', Futures 41(2): 87-95.

Bunge, Mario (1959) Causality, Cambridge, MA: Harvard University Press. 
Bunge, Mario (1963) The Myth of Simplicity: Problems of the Scientific Philosophy, Englewood Cliffs: Prentice-Hall.

Chernoff, Fred (2005) The Power of International Theory: Reforging the Link to Foreign PolicyMaking through Scientific Enquiry, London and New York: Routledge.

Cochran, Molly (2002) 'Deweyan Pragmatism and Post-Positivist Social Science in IR', Millennium 31(3): $525-48$.

Collier, Andrew (1994) Critical Realism. An Introduction to Roy Bhaskar's Philosophy, London: Verso.

Danermark, Berth, Mats Ekström, Liselotte Jakobsen and Jan Karlsson (2002) Explaining Society. Critical Realism in the Social Sciences, London and New York: Routledge.

Elder-Vass, Dave (2010) The Causal Power of Social Structures. Emergence, Structure and Agency, Cambridge: Cambridge University Press.

Ferguson, Yale H. \& Mansbach, Richard W. (2014) 'Reflections on the "Third Debate", International Studies Quarterly On-line Symposium, available at http://www.isanet.org/Publications/ISQ/Posts/ID/312/Reflections-on-the-Third-Debate.

Guzzini, Stefano (2013) 'The Ends of International Relations Theory: Stages of Reflexivity and Modes of Theorizing', European Journal of International Relations 19(3): 521-41.

Hamati-Ataya, Inanna (2012) 'Beyond (Post)Positivism: The Missed Promises of Systemic Pragmatism', International Studies Quarterly 56(2): 291-305.

Harré, Rom (1970) Principles of Scientific Thinking, London and Basingstoke: MacMillan.

Harré, Rom (1979) Social Being, Oxford: Basil Blackwell.

Harré, Rom (1986) Varieties of Realism. A Rationale for the Natural Sciences, Oxford: Basil Blackwell.

Harré, Rom and Edward H. Madden (1975) Causal Powers, Oxford: Blackwell.

Hesse, Mary (1966) Models and Analogies in Science, Notre Dame: University of Notre Dame Press. 
Humphreys, Adam (2016) 'Causation, Complexity, and the Concert: The Pragmatics of Causal Explanation in International Relations', Journal of International Relations and Development, in this issue.

Ish-Shalom, Piki (2013) Democratic Peace. A Political Biography, Ann Arbor: University of Michigan Press.

Jackson, Patrick Thaddeus (2010) The Conduct of Inquiry in International Relations: Philosophy of Science and Its Implications for the Study of World Politics, London and New York: Routledge.

Jackson, Patrick Thaddeus (2016) 'Causal Claims and Causal Explanation in International Studies', Journal of International Relations and Development, in this issue.

Jones, Martin and Bob Jessop (2010) 'Thinking State/Space Incompossibly', Antipode 42(5): 111949.

Joseph, Jonathan (2002) Hegemony: A Realist Analysis, London: Routledge.

Joseph, Jonathan (2012) The Social in the Global, Cambridge: Cambridge University Press.

Keynes, John Maynard (1920/2008) A Treatise on Probability, London: Rough Draft Printing/MacMillan.

Khong, Yuen Foong (1992) Analogies at War. Korea, Munich, Dien Bien Phu and the Vietnam Decisions of 1965, Princeton: Princeton University Press.

Kurki, Milja (2008) Causation in International Relations: Reclaiming Causal Analysis, Cambridge: Cambridge University Press.

Käpylä, Juha and Harri Mikkola (2011) 'Getting Things Right? A Reconsideration of Critical Realism as a Metatheory of IR', Journal of International Relations and Development 14(4): 401-39.

Lapid, Yosef (1989) 'The Third Debate: On the Prospects of International Theory in a Post-Positivist Era', International Studies Quarterly 33(3): 235-54.

Lawson, Tony (1997) Economics \& Reality, London and New York: Routledge. 
Lynch, Scott M. (2007) Introduction to Applied Bayesian Statistics and Estimation for Social Scientists, New York: Springer.

Mackie, John L. (1974) The Cement of the Universe, Oxford: Oxford University Press.

Næss, Petter (2004) 'Prediction, Regressions and Critical Realism', Journal of Critical Realism 3(1): $133-64$.

Patomäki, Heikki (1991) "Concepts of "Action", "Structure" and "Power" in "Critical Social Realism": A Positive and Reconstructive Critique', Journal for the Theory of Social Behaviour 21(2): 221-50.

Patomäki, Heikki (1992) 'Critical Realism and World Politics. An Explication of a Critical Theoretical and Possibilistic Methodology for the Study of World Politics', Studies on Political Science No. 12, Department of Political Science, University of Turku.

Patomäki, Heikki (1996) 'How to Tell Better Stories About World Politics', European Journal of International Relations 2(1): 105-33.

Patomäki, Heikki (2002) After International Relations. Critical Realism and the (Re)Construction of World Politics, London and New York: Routledge.

Patomäki, Heikki (2006) 'Realist Ontology for Futures Studies’, Journal of Critical Realism 5(1): 131.

Patomäki, Heikki (2008) The Political Economy of Global Security. War, Future Crises and Changes in Global Governance, London and New York: Routledge.

Patomäki, Heikki (2010a) 'Exploring Possible, Likely and Desirable Global Futures: Beyond the Closed vs. Open Systems Dichotomy', in Jonathan Joseph and Colin Wight, eds, Scientific Realism and International Relations, 147-66, London: Palgrave.

Patomäki, Heikki (2010b) 'After Critical Realism? The Relevance of Contemporary Science', Journal of Critical Realism 9(1): 59-89.

Patomäki, Heikki and Colin Wight (2000) 'After Postpositivism? The Promises of Critical Realis m', International Studies Quarterly 44(2): 213-37. 
Piketty, Thomas (2014) Capital in the Twenty-First Century, trans. by A. Goldhammer, Cambridge, MA: Belknap Press (of Harvard University Press).

Putnam, Hilary (1989) Reason, Truth and History, Cambridge: Cambridge University Press.

Rescher, Nicholas (1977) Dialectics. A Controversy-Oriented Approach to the Theory of Knowledge, Albany: State University of New York Press.

Rescher, Nicholas (1987) Forbidden Knowledge, Dordrecht: D. Reidel.

Sayer, Andrew (1992) Method in Social Science. A Realist Approach, second edition, London and New York: Routledge.

Sayer, Andrew (2000) Realism and Social Science, London: Sage.

Sayer, Andrew (2011) Why Things Matter to People: Social Science, Values and Ethical Life, Cambridge: Cambridge University Press.

Suganami, Hidemi (1996) On the Causes of War, Oxford: Clarendon Press.

Tetlock, Philip (2005) Expert Political Judgment: How Good Is It? How Can We Know?, Princeton: Princeton University Press.

Töttö, Pertti (2004) Syvällistä ja pinnallista. Teoria, empiria ja kausaalisuus sosiaalitutkimuksessa, Tampere: Vastapaino.

Wendt, Alexander (1987) 'The Agent-Structure Problem in International Relations Theory', International Organization 41(3): 335-70.

Wight, Colin (1996) 'Incommensurability and Cross-Paradigm Communication in International Relations Theory: "What's the Frequency Kenneth?", Millennium - Journal of International Studies 25(2): 291-319.

Wight, Colin (2006) Agents, Structures and International Relations: Politics as Ontology, Cambridge: Cambridge University Press.

Woodward, James (2003) Making Things Happen: A Theory of Causal Explanation, Oxford: Oxford University Press. 


\section{About the Author}

Heikki Patomäki is Professor of World Politics at the University of Helsinki, Finland. His research interests include philosophy and methodology of social sciences, peace research, futures studies, economic theory, global political economy, and global political theory. His most recent books in English are The Great Eurozone Disaster: From Crisis to Global New Deal (2013) and The Political Economy of Global Security (2008). Previously, Patomäki has worked as Professor of World Politics and Economy at the Nottingham Trent University, UK (1998-2003), and at RMIT University, Melbourne, Australia (2007-2010). In 2012, he was a Visiting Professor at the Ritsumeikan University in Kyoto, Japan. 